\title{
Capacity of female leadership
}

\author{
Xuemin Dong, a , Yingchun Wang ${ }^{2, b}$ \\ ${ }^{1}$ School of Tianjin University of Technology, Tianjin 300384 , China; \\ ${ }^{2}$ School of Tianjin University of Technology, Tianjin 300384, China. \\ a13821649794@163.com, btjycwang@gmail.com
}

\begin{abstract}
Keywords: female managers, leadership, leadership transition, leadership self-improvement.
Abstract. With the development of the times, the social status of women is gradually improving, and the scope of participation of women in social life is significantly improved, more and more women become the backbone of social management, in all areas of political, economic, social is playing an increasingly important role. The role of women in the management of enterprises was significantly enhanced, the study of women's managers continue to increase the literature. This article discusses the leadership qualities of women leaders on the basis of literature on aspects of female managers, the difficulties to be overcome, leadership transformation and leadership skills of self-improvement.
\end{abstract}

\section{Introduction}

The end of November 2015, on the 22nd individual public, consumer food science and technology policy committee at Harvard University's Kennedy School of the Government and held with the (PAPSAC) forum, "Global Dairy Top 11" Sun Yiping, president of Mengniu Dairy, as the only one from China Representatives of the food industry, summed up and share the latest trends in China's food and consumer products and Mengniu's innovative initiatives to win the attention of well-known experts, academics and business representatives from around the world [1]. She is a dedicated professional women, an outstanding female managers. With the development of economy, society, culture and education, women occupy an increasingly important position in the workplace, and those with good educational background, knowledge of women gradually to a managerial position, has become an important driving force for socio-economic development. There are more and more researches on the leadership and related factors of female managers[2].

\section{Female managers and leadership qualities}

Guanghua School of Management, the "China Women Status Managers Survey (2006) January 7, 2006 released the "advantages of female managers personal self-assessment" data is shown below.From the data of the self-assessment of female managers, we can recognize that both the female leadership and the female managers have the common leadership qualities.As can be seen from the figure, in the surveyed female managers, with a positive and progressive advantage accounted for about Bacheng[3]. There are eighty percent of women executives generally agree that they have a"proactive","hard"advantages. This characteristic of women is mainly manifested as: positive working attitude, optimistic life enthusiasm. Work attitude is a person's sense of action and external performance. Women born maternal characteristics, so that women leadership in any sense of responsibility is more intense, more serious attitude to work and life more optimistic $[4,5]$. 


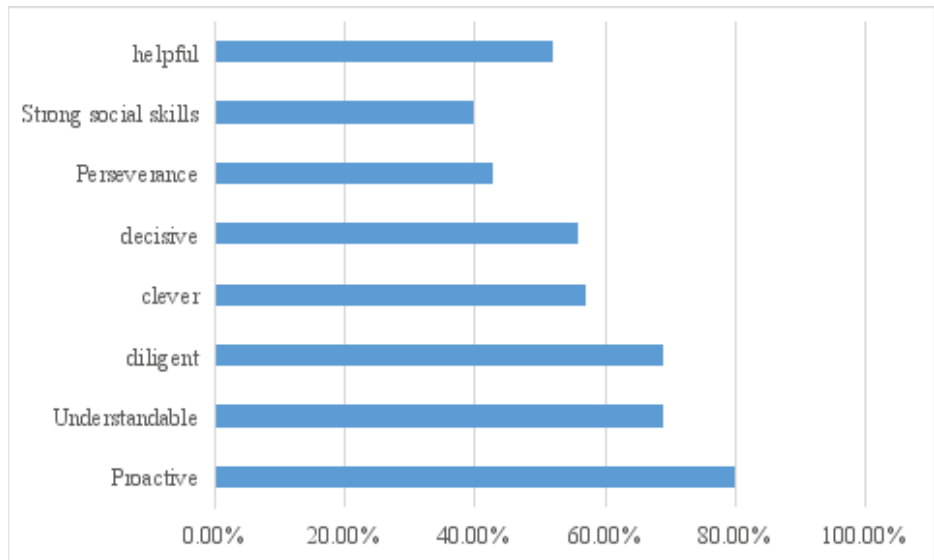

Fig. 1 Female leader personal advantage self- assessment

Women's affinity and understanding. Women's affinity is a force, giving women a better access to others, narrowing the invisible effect of distance. The female of this feature organically integrated into the leadership of science and management art. [6] Women leaders considerate, helpful traits to make them more compassionate and tolerant, more understanding of the mentality of subordinates, can empathy, so treat subordinates attitude not simply control, command, and is more to persuade, education, inspiration, etc. So that subordinates active to complete the organization's goals. Flexible management to people as the center, the staff of the personality management. System management hypertension also brought by managers of passive adaptation, "the most important feature flexible management", that it is not primarily rely on force, but on the liberation of humanity, equality of rights, democratic management, from the heart to stimulate each employee The inherent potential, initiative and creativity, as enterprises in the global market competition in the fierce competitive advantage of the source[7]. Women's unique emotional characteristics give women a gentle, alert, warm, but also gives women a keen insight, so that they can accurately grasp the key to the problem and correctly ask questions. So full of insight into the nature of women leaders insight into the complex phenomena hidden in the problem, management is more refined, more clearly the responsibility of management in place[8]. Female leaders of this kind of love will be integrated into the careful, smart integration to the fine management is the contemporary leadership of the unique leadership charm show[9].

The manager and Drucker, argues that knowledge workers are a group that pursues autonomy, individuality, diversity and innovation[10,11]. Traditional human resource management methods can not effectively motivate and manage them. They have a higher level of demand The They think that the relationship between themselves and the organization is the relationship between equality and mutual assistance. Women leaders have the characteristics of their flexible, democratic participation, focus on licensing and other leadership style, so that it is more suitable for knowledge workers on the organization and leadership of the new requirements, so that leadership is better than men[12].

\section{The leadership transition}

Significance of Women's Leadership Transition. The transformation of women's leadership is the inherent need to achieve gender balance Male managers and women managers have caused different management of their own different in the management of the work has different focus and shortcomings, women's leadership transformation from the development of women's personality to the comprehensive development of the progressive process of society. Women's leading cadres only to achieve their own ability to develop in an all-round way, to enhance their leadership in order to more widely participate in social management, the formation of an independent personality.

Meet the urgent need for social transformation. One of the characteristics of the social transition period is the change of the social organization structure, which changes from the vertical and vertical form to the horizontal flattening direction. The traditional bureaucratic system is uploaded and the top-down communication mode will be flattened. The team is replaced by a flexible organizational 
structure centered on the center. This organizational structure has a common vision to pursue, to share resources, free, open communication. Women are more emphasis on the relationship to share with others, more coherent, so in this team-style flat organizational structure, the female leadership will be more advantages. In addition, the transformation of society to people's lifestyles and values to bring profound changes. Women and men have the same responsibility to work and right to life, women have become the main bearer of the same family responsibilities. Externalized in the community, the performance of more and more women play a variety of important social role, to participate in all areas of social construction. Therefore, in order to adapt to social transformation, women's leadership transformation ready to come out[13].

Women in Leadership Transition Path Choice. Insurmountable obstacle to the heart, from egoist to achieve emotional transformation manager Compared with men, women have feelings of delicate, intuitive and so sensitive personality characteristics. This character makes some female leaders unable to go beyond the heart of the homeless, easy to fall into a self-enclosed world, become an egoist: the performance of the mind, in order to understand the narrow, self-enclosed, there are such as short-sighted, narrow-minded, and other negative manifestations, hindering its development and advancement of women; manifested in behavior, that is, when the "ideal self" and the "real self" appears contrast, a huge psychological gap, and some will not stop the former, some psychological Manic, unable to control their emotions. But today we are in a period of social transformation, social problems are increasingly complex, more and more prominent social contradictions, female leaders if you can not calmly deal, more emotional than rational, may not be able to control the situation[14]. Therefore, the female leadership in the regulation of self, to do the emotional master, good at managing their own emotions. The First, self control. That is, with the socialist core values as their own standards of scrutiny, often purposeful, consciously look at their words and deeds, with reason, willpower to overcome complaints and tension.

The role of the obstacles refers to the individual in the use of their own subjective ability to adapt to the social environment of the behavior of the pattern of deviation, mainly for the role of cognitive on the fuzzy, the role of uncertainty, the role of dislocation of consciousness, role behavior disorders.

The transformation of society, people gradually accelerated pace of life and social prejudices, so that the rhythm section is not strong female leadership or can not meet the pace of modern life, there has been work and family roles conflict. In the role of cognition, their own should be in the family and career in which the status of unclear, do not grasp, resulting in a state of mind, physical and mental fatigue, when new situations, new problems, new tasks, not Well adjust the mentality, calmly think about countermeasures, inner a loss, or even make extreme behavior. To go beyond the role of obstacles, first, the combination of subjective and objective may need accurate grasp of their role cognition and role expectations, the purpose is to find a clear role of self-image, he found the role, shaping role. Second, to understand the objective role of evaluation, do more inner self-reflection, and more family and colleagues to communicate with their own role in mind, adjust their role in the behavior, and firmly believe that they can establish their own role image[15]. Again, through the role of recognition to test their role, to establish their own role in the behavior of the model, and ultimately to achieve the balance of business and family[16].

\section{Summary}

In the social development, women "half of the sky" has become a commercial power can not be ignored, they cast their talents in the mall, to create wealth for the community, for women to win respect, which is the result of women's self-effort to create, but also China's social development and progress result. In the 1950s, Chinese women accounted for about a fifth of household income, and the 21 st century today has risen to nearly five percent, and nearly half of the women are going to work. [X] For modern women management leaders, on the one hand to make full use of and play their own excellent, unique characteristics, on the other hand should pay attention to their own limitations. On the road in the management of the courage to practice the courage to break through 
the self, and self-improvement in the management of work, take risks, dare to try, dare to take responsibility.

\section{References}

[1] Chinese women's newspaper reporter salty heart Fu Dongyan. Sun Yiping: Harvard Forum interpretation of "4D" [N]. China Women's newspaper, 2015-12-02B01.

[2] On the advantages of Enterprise Management $\mathrm{Xu}$ female managers [J] Human Resources Development, 2014,13: 64-65.

[3] Hou Zhichun, Liu Yao comparative study of rigid management and flexible management [J] Chinese and foreign entrepreneurs, 2014,27: 84.

[4] Yang Jing, Wang Kun. Women's leadership research review and outlook [J]. Journal of Shandong University of Finance and Economics, 2015,04: 111-117.

[5] Zhao Hongyan. Female managers in the enterprise development of the advantages of sudden [J]. Yunnan Science and Technology Management, 2013,03: 30-33.

[6] Wei Hong. Female leadership characteristics and leadership transformation [J]. Leadership Science, 2015, 16: 46-48.

[7] Ning Benrong. Women's leadership self-improvement of the "barrier" and "broken barrier" [J]. Leadership Science, 2014,33: 46-47.

[8] Luo Yuliang. Female leaders to overcome the "fickle" behavior [J]. Leadership Science, 2015,07: 45-46.

[9] Liu Shimin, Liu Miao. Women's career development in the "glass ceiling" effect [J]. Dong Yue Lun, 2015,04: 184-187.

[10] Zhang Meng. On women leaders in the enterprise management indispensable role [J]. Electronic production, 2015,05: 277.

[11]Chin-Chung (Joy) Chao. Climbing the Himalayas: A cross-cultural analysis of female leadership and glass ceiling effects in non-profit organizations[J]. Leadership \& Organization Development Journal,2011,32(8).

[12]Linzi J. Kemp,Susan R. Madsen,Mohammed El-Saidi. The current state of female leadership in the United Arab Emirates[J]. Journal of Global Responsibility,2013,4(1).

[13]Yusuf M. Sidani,Alison Konrad,Charlotte M. Karam. From female leadership advantage to female leadership deficit[J]. Career Development International,2015,20(3).

[14]Kvaerner K J,Aasland O G,Botten G S. Female medical leadership: cross sectional study.[J]. BMJ (Clinical research ed.),1999,318(7176).

[15]Gurman E B,Long K. Emergent leadership and female sex role identity.[J]. The Journal of psychology,1992,126(3).

[16]Martell R F,Desmet A L. A diagnostic-ratio approach to measuring beliefs about the leadership abilities of male and female managers.[J]. Journal of Applied Psychology,2002,86(6). 